\title{
Modification of sodium lignosulfonate with reagent obtaining for drilling fluids
}

\author{
R.A. Fedina \\ Applicant of the Department of Physical and Organic Chemistry, Federal State Budgetary Educational \\ Institution of Higher Education Ufa State Petroleum Technological University, Ufa, Russia
}

\begin{abstract}
A.D. Badikova
Doctor of Engineering Sciences, Professor, Head of the Department of Physical and Organic Chemistry, Federal State Budgetary Educational Institution of Higher Education Ufa State Petroleum Technological University, Ufa, Russia

I.N. Kulyashova

Candidate of Engineering Sciences, Head of laboratory of the Department of Physical and Organic Chemistry, Federal State Budgetary Educational Institution of Higher Education Ufa State Petroleum Technological University, Ufa, Russia
\end{abstract}

\section{D.A. Dubovtsev}

Master's Degree Student of the Department of Oil and Gas Technology, Federal State Budgetary Educational Institution of Higher Education Ufa State Petroleum Technological University, Ufa, Russia

\section{M.A. Tsadkin}

Doctor of Engineering Sciences, Professor of the Department of High-molecular Compounds and General Chemical Technology, Federal State Budgetary Educational Institution of Higher Education Bashkir State University, Ufa, Russia

\begin{abstract}
Analysis of lignosulfonate drilling reagents showed that the reagents based on modified lignosulfonates, that is ferrochrome lignosulfonates (FCLS) are part of most drilling fluids. However, the content of toxic chromium $(2.0-3.5 \% \mathrm{wt})$, high bottomhole temperatures $\left(150-190^{\circ} \mathrm{C}\right)$, as well as a decrease in the volume and quality of sulfite lignosulfonate, which is the main source of raw materials, limits the possibility to use them. To obtain an effective drilling reagent capable of regulating the properties of the drilling fluid, the basic method for modifying the neutral sulfite lignosulfonate to produce drilling reagents with high qualitative characteristics has been improved - the liquefaction index is up to $60 \%$, the filtration index is $6.0-6.5 \mathrm{~cm}^{3} / 30 \mathrm{~min}$, the nominal viscosity is $24 \mathrm{~s}$, and to increase the stability and resistance of the washing (drilling) liquid to temperature aggression, additional modifiers containing phosphonic compounds are introduced.
\end{abstract}

Keywords: sodium lignosulfonate, neutral sulfite liquor, modification, phosphonic compounds, drilling reagent, infrared spectroscopy (IR spectroscopy), X-ray fluorescence (XRF)

\section{INTRODUCTION}

In drilling, a group of reagents based on lignosulfonates is widely used, i.e. oxidized and chromium-substituted lignosulfonate (oxyl), ferrochrome lignosulfonate (FCLS), spent sulfitealcohol liquor (SSAL), sulfite yeast mash (SYM), condensed spent sulfite-alcohol liquor 
(CSSAL), etc. The main disadvantage of these reagents is the weak effect under conditions of high bottomhole temperatures.

Acrylic polymers, in particular, gipan, metas, K-4, M-14, Lacris-20, and others, are very resistant to heat. However, their use is not always effective because of their instability to polyvalent metal salts, for example, to the effect of calcium ions; the high cost of imported macromolecular substances and the scarcity of domestic ones (the needs for polymer reagents are satisfied only by $40-50 \%$ ) (Komkova, 2011).

Tretyak A.Ya. proposed a drilling fluid containing $0.5-2.0 \%$ carboxymethyl cellulose, dextrin crumb, which is a mixture of hydrocarbons formed during the hydrolysis of potato and maize starch $0.5-3.0 \%$ and water (Pat. RF 2038362, 1995). Dextrin crumb is a colmatation filler, and the rest of the solution is very sensitive to polysalt mineralization, so the use of this solution is limited, it can be used only in fresh systems.

The same author proposed the composition of the solution containing $0.5-3.0 \%$ dextrin groats, $0.5-2.0 \% \mathrm{CMC}, 0.1 \%$ sodium hydroxide and water (Bulatov et al., 1999). The presence of caustic soda creates an increased $\mathrm{pH}$ value of the medium (up to 14), which limits their use under conditions of using aluminum pipes and adversely affects the stability of the borehole walls (Kulyashova, 2016).

An analysis of the papers of domestic and foreign researchers showed that the most optimal stabilizing reagents for mineralization conditions and high temperatures may be linear polymeric substances containing non-ionic functional groups that provide optimal adsorption on the solid phase (Komkova, 2011).

A method of obtaining a reagent for processing drilling fluids (Levik, 1982) is known, including the oxidation of spent sulfite-alcohol liquor with alkali metal dichromates, followed by condensation, where the oxidation and condensation being carried out for 1-2 hours at 20$30^{\circ} \mathrm{C}$ at $\mathrm{pH}$ 6.0-6.5 of the initial raw mixture in the presence of fatty acids of vegetable oils. The disadvantage is that due to high $\mathrm{pH}$ and reaction medium dilution, a low degree polycondensation reagent is formed and as a sequence of this, with lower stabilization efficiency and reduced filtration of drilling fluids. In addition, the reagent is used in overdosages.

A method of obtaining a reagent is also known (Pat. RF 2152419, 2000), which is constant in composition and qualitative characteristics, with high performance properties, obtained by polycondensation of lignosulfonates with formaldehyde and a co-condensing agent in an aqueous medium with an acid catalyst when heated, followed by neutralization of the reaction mass with alkali metal hydroxides, characterized in that polycondensation is carried out stepwise: initially, lignosulfonates interact with formaldehyde, then into the reaction mass a co-condensing reagent is introduced and additional polycondensation is carried out, and the neutralized reaction mass is dried. The disadvantage of this production method is that it is proposed to use highly toxic phenol, phenolsulfonic acid, etc., as a co-condensing reagent, which increases the environmental risks when using this drilling reagent.

In the structure of lignosulfonates, there are active centers capable of entering into the polycondensation reaction (of the phenolaldehyde type) with the enlargement of the starting substances (Bulatov et al., 1999). This leads to an increase in the antifiltration and thermostabilizing properties of condensed lignosulfonates as reagents for drilling fluids. Condensed lignosulfonates are obtained, for example, by their interaction with formaldehyde in an aqueous medium when heated with an acid catalyst (Badikova, 2014). The disadvantage is condensed lignosulfonates (CSSAL) are ineffective in the presence of sodium chloride and at high temperatures (Pat. RF 2098447, 1997).

Lignosulfonate macromolecules are disordered, branched helices with varying degrees of compaction. Low molecular fractions can be of a linear structure. Polydispersity, the presence of ionogenic groups, and a high degree of molecular dissociation indicate that strongly associated highly hydrophilic polyions should prevail in the solution. The structure of lignosulfonates in the shape of polyaromatic chains with functional groups included in them, determines their diphilic nature, surface activity, and high adsorption activity (Badikova et al., 2014).

The qualitative and quantitative composition of lignosulfonates obtained during the wood delignification process depends on the main chemical processes timing during various cooking 
methods, on the properties of the wood components with which cooking solutions react, as well as on the composition of cooking solutions and cooking conditions (Kulyashova, 2016).

The problem for the further use of lignosulfonate reagents today is a decrease in the production of sulfite lignosulfonates due to a change in the raw material base and the consistent transition of pulp and paper mills to neutral sulfite methods of technical lignosulfonate production. The resulting products are characterized by a reduced content of the main component, that is lignosulfonate (not more than $49 \%$ of the mass, unlike sulfite $-60 \%$ of the mass), consisting mainly of low molecular fractions, and also containing insoluble components in the composition (Pat. RF 2038362, 1995). Neutral sulfite liquor is of undoubted interest, since a large proportion of organic substances in it are carbohydrates and salts of low molecular organic acids. However, the possibility of individual use of neutral sulfite liquor requires its modification to obtain a reagent that is stable during electrolyte and temperature aggression and does not adversely affect other properties of the working solution (Badikova et al., 2014). A distinctive feature of drilling reagents obtained by the modification of lignosulfonates is the dependence of their physical and chemical and technological parameters on the quality of the raw material base (Komkova, 2011; Badikova et al., 2016).

In industry, obtaining the ferrochrome lignosulfonate (FCLS) is carried out by modifying the technical lignosulfonate with iron and chromium compounds, followed by neutralization with caustic soda, and then dried to a powder state (Levik, 1982).

However, the industrial obtaining of chrome lignosulfonates is associated with a number of issues, such as the formation of a chromic production waste, incomplete reduction of anionic chromium compounds in the composition of the resulting drilling reagent (Kulyashova, 2016; Badikova et al., 2016)

In this regard, the aim of this paper was to obtain and study the properties of a modified lignosulfonate drilling reagent for effective drilling fluids.

\section{MATERIALS AND METHODS}

In this paper, lignosulfonates of various cooking methods were used as raw materials for obtaining drilling reagents: sulfite STO (Corporate Standard) 43508418-022-2010 and neutral sulfite TU (Technical Standards) 2455-101-72197712-2013; modifiers, that is iron sulfate as per GOST (State Standard) 6981, sodium dichromate, as per GOST (State Standard) 2651; NTF (nitrilotrimethylphosphonic acid) modifiers TU (Technical Standards) 2439-34705763441-2001 and TPF (sodium tripolyphosphate) GOST (State Standard) 13493-86 containing phosphonic groups (Badikova et al., 2016).

A drilling reagent based on lignosulfonate modified with salts of polyvalent metals (iron and chromium), manufactured under the trade name of FCLS (ferrochrome lignosulfonate), corresponding to quality indicators, was chosen as an industrial analogue.

Quality indicators of a FCLS reagent are as follows: mass fraction of water is no more than $10 \%$; solubility in water is at least $90 \%$; $\mathrm{pH}$ of a $1 \%$ aqueous solution is in the range of $4.0-5.0$; a dilution rate is at least $50 \%$.

The process of obtaining sulfite liquors, until today, has been predominant and met all the necessary requirements: cheap starting chemicals, high yield of cellulose, the ability to easily obtain from by-products while complying with environmental requirements. However, at present, the standards for the content of pollution in wastewater and gas emissions are tightened, there is a decrease in the quality of the raw materials used for the sulfite cooking method. As a result, pulp and paper mills switch to the processing of low-grade raw materials in a neutral sulfite method that meets environmental safety requirements and contributes to the production of technical lignosulfonates with a reduced content of the main component, that is lignosulfonate (not more than $49 \%$ of the mass, unlike sulfite - $60 \%$ of the mass), and consists mainly of low molecular fractions (up to $7500 \mathrm{amu}$, in contrast to sulphite, up to 20,000 amu), and also contains insoluble substances, which makes it impossible to obtain reagents of appropriate quality. 
In this regard, additional modification of the lignosulfonate was carried out with compounds containing phosphonic groups (Kulyashova, 2016; Pat. RF 2574659).

Modification of the lignosulfonate feed was carried out as follows: iron (II) sulfate was introduced into the mass of technical lignosulfonate. The mass was maintained with constant stirring for 1.0-1.5 hours at a temperature of $30-40^{\circ} \mathrm{C}$. Sodium dichromate was introduced into the resulting mass in the form of an aqueous $15-20 \%$ solution. The mass was maintained with constant stirring for 1 hour at a temperature of $30-40^{\circ} \mathrm{C}$. Then, a modifying agent was introduced, in the form of an aqueous solution, and again kept for 1 hour under the same conditions. The finished liquid product was neutralized with caustic soda to $\mathrm{pH}=3.5-5.0$. The finished mass was dried to a powder state, first at atmospheric pressure at a temperature of $65 \div 85^{\circ} \mathrm{C}$, then in a vacuum oven to a constant weight (Kulyashova, 2016). The obtained experimental drilling reagents were analyzed according to the requirements of analytical control adopted in the production of reagents that regulate the quality of a drilling fluid (Badikova et al., 2014).

\section{RESULTS AND DISCUSSION}

As raw materials for obtaining experimental modified lignosulfonate drilling reagents, technical aqueous solutions of lignosulfonates of various cooking methods were used: sulfite and neutral sulfite.

As shown in the references (Badikova et al., 2016; Teptereva et al., 2015), the qualitative characteristics of the obtained drilling reagents are directly conditioned by the chemical composition of the sources of raw materials (sulfite and neutral sulfite lignosulfonate) and modifiers containing phosphophonic groups.

A comparative analysis of the content of functional groups in lignosulfonate feedstock and modified drilling reagents based on it has been carried out. The determination has been carried out by IR spectrometry. The spectra were recorded on a FTIR-8400S (Shimadzu) FT-IR spectrometer in the range $700-4000 \mathrm{~cm}^{-1}$ with a device resolution of $4 \mathrm{~cm}^{-1}$.

The obtained IR spectra (Figure 1) of lignosulfonates are characterized by the following absorption bands: $1039-1089 \mathrm{~cm}^{-1}$ (SO3 groups); 3200-3600 $\mathrm{cm}^{-1}$ (OH groups); 1521 and $1558 \mathrm{~cm}^{-1}$ (substituted aromatic lignin ring); $1379 \mathrm{~cm}^{-1}$ relate to symmetric vibrations of the terminal methyl group; $1456,1458 \mathrm{~cm}^{-1}$ is the total content of methylene and methyl groups (Kazitsyna et al., 1971).

Figure 1 shows the IR spectrum of the experimental lignosulfonate sample modified with a compound containing phosphonic groups.

The presence of sulfogroups in the lignosulfonate macromolecule gives hydrophilic properties to a water-insoluble polymer.

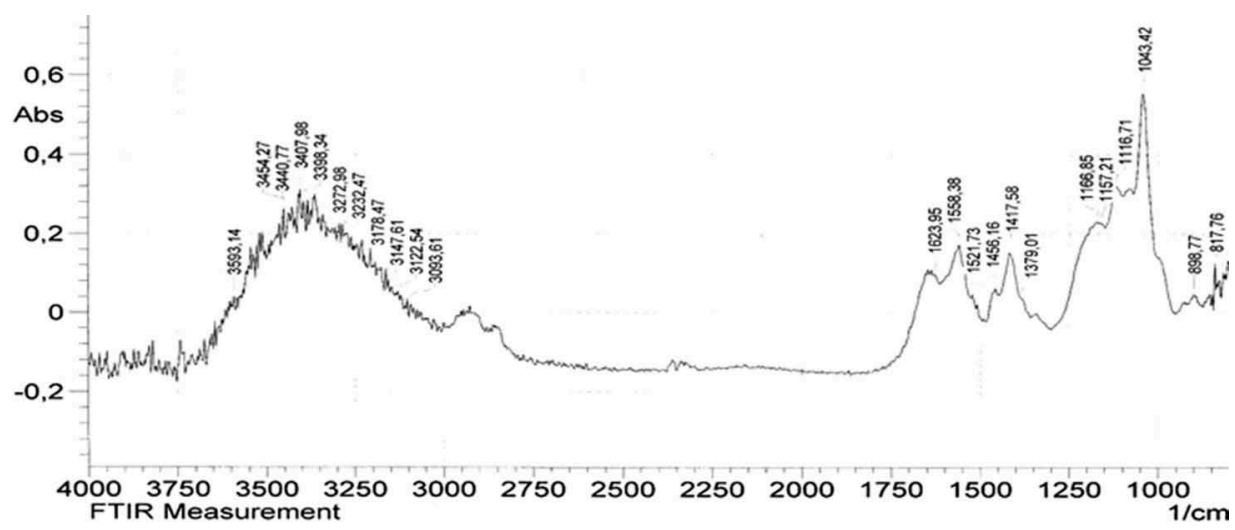

Figure 1. IR spectra of the ferrochrome lignosulfonate sample + TPF (sodium tripolyphosphate). 
According to the obtained analysis data by IR spectrometry, it was shown that the samples of modified lignosulfonate reagents were almost identical in the content of functional groups. In the infrared spectrum of the lignosulfonate modified with compounds containing phosphonic groups, absorption bands of the associated $\mathrm{P}=\mathrm{O}$ bond are observed in the region of $1157-1166 \mathrm{~cm}^{-1}$, which is presumably illustrative of the formation of an additional complex between the phosphonic group introduced into the carboxyl group of the phenylpropane unit of the lignosulfonate, and mainly iron cation (Kazitsyna et al., 1971).

To determine the thermal stability of the reagents tested, a clay mud prepared from Serpukhov mud powder of ПБМВ (PВМV) brand with the following parameters was taken as the basis: NV (nominal viscosity) $=64 \mathrm{~s}$, FI (filtration index $)=18 \mathrm{~cm}^{3} / 30 \mathrm{~min}, \eta_{\mathrm{pl}}\left(\eta_{\text {plastic viscosity }}\right)$ $=16 \mathrm{mPas}, \tau_{0}=68 \mathrm{dPa}$ (dynamic shear stress), SSS (static shear stress) ${ }_{1 / 10}=50 / 64 \mathrm{dPa}$. The obtained modified drilling reagents were introduced into the clay drilling mud and analyzed according to the GOST analysis methods (Kister, 1972; Darley et al., 1988). The results are presented in Table 1.

The influence of temperature in the range from $20^{\circ} \mathrm{C}$ up to $190^{\circ} \mathrm{C}$ on the change in technological parameters of the clay mud was determined when the sample was kept for 3 hours in the aging cell 'BOMBA A-B-05' (BOMB A-B-05).

Based on the results obtained in Table 1, it was found that an industrial sample of a drilling reagent, ferrochrome lignosulfonate, is able to effectively reduce the nominal viscosity from 64 up to $30 \mathrm{~s}$, filtering from 18 up to $6 \mathrm{~cm}^{3} / 30 \mathrm{~min}$, plastic (from 16 up to $12 \mathrm{mPas}$ ) and dynamic viscosity from 68 up to $52 \mathrm{dPa}$, static shear stress from 50/64 up to 15/45 dPa of No. 2 drilling mud with respect to No. 1 initial clay drilling mud. However, drilling fluids are used in a wide variety of mining and geological conditions, for example, when drilling wells at elevated bottomhole temperatures. The influence of temperature on No. 3 drilling fluid in the range up to $190^{\circ}$ leads to a decrease in qualitative indicators.

When a drilling reagent based on neutral sulfite liquor modified with TPF (sodium tripolyphosphate) is introduced into No. 5 drilling mud, the nominal viscosity decreases from $64 \mathrm{~s}$ up to $36 \mathrm{~s}$ and at the same time the heat resistance increases up to $190^{\circ} \mathrm{C}$.

When nitriletrimethylenephosphonic acid is modified with a ferrochrome lignosulfonate reagent based on neutral sulfite liquor in No. 4 drilling fluid, the nominal viscosity decreases from $64 \mathrm{~s}$ up to $34 \mathrm{~s}$, and it was found that at a concentration of $1 \%$ of the mass of introduced modifiers with complex containing properties, the best qualitative indicators were determined, filtration index: $6.5 \mathrm{~cm}^{3} / 30 \mathrm{~min}$. The addition of FCLS based on sulfite liquor, modified NTF and TPF to drilling fluids No. 6 and 7, reduces the nominal viscosity of No. 1 initial clay

Table 1. The effect of reagents on the parameters of clay drilling mud.

\begin{tabular}{|c|c|c|c|c|c|c|c|c|c|c|}
\hline \multirow[b]{3}{*}{ № } & \multirow[b]{3}{*}{ Solution composition } & \multirow[b]{3}{*}{$\begin{array}{l}\mathrm{T},{ }^{\circ} \mathrm{C} \\
3 \mathrm{~h}\end{array}$} & \multicolumn{8}{|c|}{ Solution Properties } \\
\hline & & & \multirow[b]{2}{*}{$\begin{array}{l}\rho, \\
\mathrm{g} / \mathrm{cm}^{3}\end{array}$} & \multirow[b]{2}{*}{$\mathrm{NV}, \mathrm{s}$} & \multirow[b]{2}{*}{$\begin{array}{l}\eta_{\mathrm{pl}}, \\
\mathrm{mPas}\end{array}$} & \multirow[b]{2}{*}{$\begin{array}{l}\tau_{0} \\
\mathrm{dPa}\end{array}$} & \multicolumn{2}{|c|}{$\mathrm{SSS}, \mathrm{dPa}$} & \multirow{2}{*}{$\begin{array}{l}\mathrm{FI}, \\
\mathrm{cm}^{3} / 30 \\
\min \end{array}$} & \multirow[b]{2}{*}{$\mathrm{pH}$} \\
\hline & & & & & & & $1 \mathrm{~min}$ & $10 \mathrm{~min}$ & & \\
\hline 1 & Initial clay mud (ICM) & 20 & 1.08 & 64 & 16 & 68 & 50 & 64 & 18.0 & 9.0 \\
\hline 2 & $\mathrm{ICM}+1 \% \mathrm{FCLS}^{*}$ & 20 & 1.09 & 30 & 12 & 52 & 15 & 45 & 6.0 & 9.0 \\
\hline 3 & ICM+1\% FCLS* & 190 & 1.08 & 64 & 14 & 98 & 87 & 105 & 9.0 & 9.1 \\
\hline 4 & $\mathrm{ICM}+1 \% \mathrm{FCLS}^{*}+\mathrm{NTF}$ & 190 & 1.07 & 34 & 14 & 57 & 15 & 44 & 6.5 & 9.0 \\
\hline 5 & $\mathrm{ICM}+1 \%$ FCLS $*+\mathrm{TPF}$ & 190 & 1.08 & 36 & 14 & 55 & 17 & 45 & 6.5 & 9.0 \\
\hline 6 & $\mathrm{ICM}+1 \%$ FCLS $* *+\mathrm{NTF}$ & 195 & 1.06 & 25 & 14 & 57 & 15 & 44 & 18.0 & 9.0 \\
\hline 7 & $\mathrm{ICM}+1 \% \mathrm{FCLS} * *+\mathrm{TPF}$ & 195 & 1.04 & 30 & 15 & 56 & 15 & 42 & 16.0 & 9.0 \\
\hline
\end{tabular}

* based on NSC (neutral sulfite liquor),

** based on SC (sulfite liquor),

Note: $\rho, \mathrm{g} / \mathrm{cm} 3$ - density; NV, s - nominal viscosity; $\eta_{\mathrm{pl}}$, mPas - plastic viscosity; $\tau_{0}$, mPas - relative viscosity; $\mathrm{SSS}, \mathrm{dPa}$ - static shear stress; FI, $\mathrm{cm}^{3} / 30 \mathrm{~min}$ - filtration index; $\mathrm{pH}-\mathrm{pH}$ (hydrogen) index. 
drilling mud from 64 up to $25-30 \mathrm{~s}$, and the filtration indexes remain almost unchanged compared to ICM No. 1.

According to the research results the influence of drilling reagents on the parameters of clay drilling mud, it was shown that the introduction of modifying agents made it possible to preserve, and in some cases improve the main qualitative characteristics, i.e. nominal viscosity and filtration index, and, among the modifiers used, the best results were achieved with the introduction of NTF or TPF containing phosphonic groups in a drilling reagent based on neutral sulfite liquor, preserving the parameters of drilling fluids No. 4 and 5, even at a temperature up to $190^{\circ} \mathrm{C}$.

Modification of lignosulfonates by cations of polyvalent metals that are part of iron sulfate and sodium dichromate in order to obtain ferrochrome lignosulfonates results reagent obtaining, that is a viscosity reducing agent, which is used in a wide range of temperatures and under various conditions (Hornof et al., 1981).

The main qualitative characteristics proved that modified drilling reagents based on neutral sulfite liquor can preserve the property of drilling fluids even at elevated temperatures up to $190^{\circ} \mathrm{C}$.

In this regard, a thermogravimetric analysis of a modified drilling reagent sample for thermal stability was carried out on a TGA-DSC instrument ('Mettler Toledo' company). For this, a weighed portion of the test sample $(5-15 \mathrm{mg})$ was placed in an alumina crucible with a volume of $70 \mu \mathrm{l}$. The measurements were carried out in the temperature range from $25^{\circ} \mathrm{C}$ up to $220^{\circ} \mathrm{C}$ at a heating rate of $5 \mathrm{deg} / \mathrm{min}$, the atmosphere - air, nitrogen. According to the results of a thermogravimetric analysis of lignosulfonate raw materials and reagents obtained on its basis, it was shown that the temperature of the beginning of decomposition in the raw materials in a neutral sulfite cooking method was $150^{\circ} \mathrm{C}$; and in modified drilling reagents was $190^{\circ} \mathrm{C}$ and $200^{\circ} \mathrm{C}$, respectively.

The content of iron and chromium compounds was determined by an energy dispersive $\mathrm{X}$-ray fluorescence analysis.

The elemental composition of the drilling reagent samples was determined on an EDX-800 Shimadzu energy dispersive X-ray fluorescence spectrometer with an X-ray tube with a rhodium anode under the following conditions: voltage $15-50 \mathrm{kV}$, current $20-1000 \mu \mathrm{A}$, in vacuum atmosphere, collimator $5 \mathrm{~mm}$, measurement time $15 \mathrm{~min}$. The analysis was carried out by the method of fundamental parameters, provided by software support of the device, using the measurement channels [Ti-U], [C-Sc], [S-K].

Samples for determining the elemental composition undergo minimal preliminary preparation. The sample powder is pressed into tablets on a boric acid substrate by the press at the pressure of 10-15 t (Badikova et al., 2016).

As an example, the results of the analysis of FCLS (industrial analogue) and FCLS + NTF (modified experimental reagent based on neutral sulfite liquor) are shown (Table 2).

The analysis shows that the composition is represented by 10 components. It should be noted that the calculation of the content of elements in the samples is carried out by the

Table 2. Results of comparative laboratory tests of the elemental composition.

\begin{tabular}{lrr}
\hline Analit & FCLS industrial & FCLS + NTF \\
\hline $\mathrm{S}$ & $21.482 \pm 0.04$ & $13.324 \pm 0.65$ \\
$\mathrm{Na}$ & $9.094 \pm 0.84$ & $3.877 \pm 0.44$ \\
$\mathrm{Fe}$ & $0.998 \pm 0.01$ & $0.849 \pm 0.01$ \\
$\mathrm{P}$ & $0.986 \pm 0.02$ & $2.754 \pm 0.11$ \\
$\mathrm{Cr}$ & $2.089 \pm 0.01$ & $0.450 \pm 0.02$ \\
$\mathrm{~K}$ & $0.579 \pm 0.03$ & $0.091 \pm 0.12$ \\
$\mathrm{Ca}$ & $0.241 \pm 0.17$ & $0.138 \pm 0.01$ \\
$\mathrm{Si}$ & $0.256 \pm 0.03$ & $0.191 \pm 0.02$ \\
$\mathrm{Cl}$ & $0.107 \pm 0.09$ & $0.072 \pm 0.05$ \\
$\mathrm{C}$ & $64.167 \pm 0.26$ & $78.159 \pm 1.35$ \\
\hline
\end{tabular}


method of fundamental parameters; the determination of elements in the form of oxides without the possibility of indicating valence is carried out formally according to the spectrometer software. C content should be considered as an organic component of the sample. The iron content in FCLS is $0.998 \%$ wt., and in the experimental sample is $0.849 \% \mathrm{wt}$.; chromium in FCLS is $2.089 \%$ wt., experimental reagent is $0.450 \% \mathrm{wt}$. The results are confirmed by the spectra.

According to the spectra, the elemental composition of the drilling reagents presented is consistent with tabular photon energies of the main lines of $\mathrm{K}$-series $(\alpha, \beta)$ and L-series $(\alpha, \beta)$.

According to the data obtained, it was found that the samples are comparable in terms of the basic elemental composition, but a decrease is observed in the chromium content in the developed modified reagent up to $0.450 \%$ wt. as compared with the industrial analogue of FCLS $(2.089 \%$ wt.), which contributes to a significant reduction in environmental risks when using an experimental reagent.

\section{CONCLUSIONS}

It was found that when modifying a ferrochromolignosulfonate reagent based on neutral sulfite liquor and/or sulfite liquor with phosphonic compounds, a drilling reagent with improved quality characteristics was obtained: the nominal viscosity is $34 \mathrm{~s}$ and $25-30 \mathrm{~s}$, the filtration index is $6.5 \mathrm{~cm}^{3} / 30 \mathrm{~min}$ and $16-18 \mathrm{~cm}^{3} / 30 \mathrm{~min}$, respectively.

The presented methodology for the modification of the lignosulfonate reagent makes it possible to obtain a drilling reagent, which is stable at high bottomhole temperatures $\left(190-195^{\circ} \mathrm{C}\right)$ and meet the environmental safety requirements by reducing the content of iron to $0.85 \%$ by weight. and chromium up to $0.45 \%$ by weight.

\section{REFERENCES}

Badikova A.D., Kulyashova I.N., Teptereva G.A., Kudasheva F.Kh., Konstantinov K.N. 2009. The effect of lignosulfonate tannidity on the rate of drilling fluid reagent dilution Series: Chemistry and Chemical Technology, V. 52, No. 4, pp. 69-70.

Badikova A.D., Yalalova R.A., Kulyashova I.N., Alekhina I.E., Tashbulatova V.F. 2016. Determination of chromium and iron in the composition of modified lignosulfonate drilling reagents by X-ray fluorescence analysis, Bulletin of the University of Bashkir, T. 21, No. 4, S. 931-934.

Badikova A.D., Yalalova R.A., Kulyashova I.N., Kudasheva F.Kh., Tsadkin M.A., Mortikov E.S. 2016 Modification of neutral sulfite liquors to obtain lignosulfonate drilling reagents, Chemistry and Technology of Fuels and Oils, 2016, No. 6 (598), P. 21-24.

Badikova A.D., Kulyashova I. N., Kudasheva F. Kh. 2014 Lignosulfonates of the neutral sulfite cooking method as a promising raw material for producing drilling reagents, Bashkir Chemical Journal, 2014, V. 21, No. 1, P. 64-66.

Bulatov, A.I., Makarenko P.P., Proselkov Yi. N. 1999. Drilling flushing and grouting solutions: a textbook for universities, M. Nedra, 1999, 424 pp.

Darley H.C.H., Gray G.R., 5th edition. Houston, TX: Gulf Professional Publishing, 1988, 643 p.

Hornof V., Neal G., Bourgeois P., Canad. J., Chem. Engng, 1981, Vol. 59, No. 8, p. 554

Kazitsyna L.A., Kupletskaya N.B. 1971. The use of UV, IR, NMR and mass spectroscopy in organic chemistry: a textbook for universities, M. Higher School, $240 \mathrm{pp.}$

Kister E.G. 1972. Chemical treatment of drilling fluids, M. Nedra, 392 P.

Komkova, L.P. 2011. Improving the quality of drilling drilling fluids using modified lignosulfonates: Abstract. dis. ... cand. tech. Sciences: 25.00.15.: 1-24.

Kulyashova, I.N. 2016. Improving the quality of drilling drilling fluids with modified neutral sulfite lignosulfonates: Abstract. dis. ... cand. tech. Sciences: 25.00.15.: 1-23.

Levik N.P. 1982. A.S. 956537 USSR. 1982, No. 33, 1 p.

Lurie Yu. Yu. 1984. Chemical analysis of industrial wastewater, M. Chemistry, $142 \mathrm{pp.}$

Lurie Yu. Yu. 1971. Unified methods of water analysis, M. Chemistry, 375 pp.

Pat. 2098447 Russian Federation, IPC C09K 7/00 (1995.01) A method for producing a lignosulfonate reagent for drilling fluids. 95109485/03 Decl. 06/06/1995, publ. 12/ 10/1997. 
Pat. 2038362 Russian Federation, IPC C09K 7/02 (1995.01) Drilling fluid. 93014619/03 Declared 03/ 22/ 1993,publ. 06/27/1995.

Pat. 2574659 Russian Federation, IPC C09K 8/03 (2006.01) A method for producing reagents for processing drilling fluids. 2015100383/03 Declared 01/ 12/2015,publ. 02/ 10/2016.

Pat. 2152419 Russian Federation, IPC C09K 7/02 (2000.01) A method for producing a lignosulfonate reagent for drilling fluids. 98116713/03 Decl. 09/ 07/1998,publ. 07/10/2000.

Teptereva G.A., Kulyashova I.N., Asfandiyarov L.Kh., Konesev G.V., Badikova A.D., Chetvertneva I. A. 2015. Reactivity of sulfite liquors as the basis of drilling reagents, Oil and Gas Business, No. 3, P. 91 